\title{
KONSENTRASI SEDIMEN SUSPENSI PADA BELOKAN 57º SALURAN TERBUKA
}

\author{
ADY PURNAMA ${ }^{1}$ \\ ${ }^{1}$ Dosen Program Studi Teknik Sipil Fakultas Teknik dan Informatika Universitas Samawa
}

\begin{abstract}
Absract
Predicting the behavior of the flow in the channel turned quite important, because the channel has turned a fairly high level prone to water damage when compared with the straight line. A phenomenon that often occurs and causes kerugikan in turn channel is the sediment transport phenomena.

The phenomenon that occurs in the channel turn can be detected by performing measurements directly in the field. For a case study of parent channel mataram, the research done by measurement of sediment concentration profiles using the tool opcon suspension. The study was conducted on curves that have the angle, $\alpha=57^{\circ}$ with $r=50 \mathrm{~m}$. From the analysis of the measurements of the concentration of sediment suspensions carried out in an open channel with a bend $57^{\circ}$, indicating that the concentration of sediment suspension had a trend which is almost equal to the entire face, ie the concentration of sediment suspension is increased toward the base line and decreasing toward the surface of the water with the trend of distribution more upright with values more uniform towards the water surface. In the transverse direction, the concentration of sediment suspension tends to increase toward the inside of the bend when passing through the initial turn, then decreases towards the inside of the bend as it passes through the middle of the turn, and again increased toward the inside of the bend as it passes through the final turn which resulted in the deposition on the inside of the turn ( inner bank) and erosion on the outer side of the bend (outer bank) on the basis of the channel. For the analysis of sediment suspension concentration field measurement results are compared with the analysis of the rouse equation and the equation tanaka-sugimoto show that enough measurement data can predict sediment concentration suspension on curves, although the angle and radius of the bend is varied. Suspension of sediment measurement data value is closer to the data analysis results rouse and tanaka-sugimoto. The results of the analysis of tanakasugimoto could provide better results than analysis rouse.
\end{abstract}

Keywords: sediment concentration of the suspension, turn the channel, rouse method, the method of tanaka-sugimoto.

\section{PENDAHULUAN}

Memprediksi perilaku aliran pada saluran terbuka di belokan cukup penting, karena saluran tidak selamanya lurus dan akan tetap ada belokan disepanjang saluran sehingga alur aliran yang melalui saluran akan terpengaruh oleh belokan tersebut. Seperti halnya sungai yang mempunyai bentuk fisik yang bervariatif sehingga pola alirannya sangat kompleks dengan karakteristik yang khusus. Secara umum, faktor yang mempengaruhi aliran pada belokan adalah gaya sentrifugal akibat kelengkungan aliran, ketidakseragaman kecepatan tampang vertikal, tekanan pada potongan, dan gradien tekanan arah radial yang disebabkan oleh kemiringan lateral permukaan air (Chow 1959). Hal yang tak kalah penting dari perilaku kecepatan aliran pada belokan adalah perilaku sedimen (transport sedimen). Transpor sedimen yang terjadi pada saluran terbuka, sungai dan waduk merupakan peristiwa yang sangat komplek. Proses terjadinya pendangkalan sungai sebagai akibat dari proses erosi (scouring) pada bagian hulu sungai, yang mengakibatkan terjadinya angkutan sedimen ke hilir. Aliran air yang mengandung sedimen akan mengendapkan terlebih dahulu butiran kasar (bed load) dibandingkan dengan butiran halus (suspended load) yang akan terus melayang mengikuti aliran air. Kondisi seperti inilah yang kadang menjadi permasalahan dalam pemanfaatan air 
sungai. Oleh karena itu, pengetahuan mengenai kuantitas dan karakteristik sedimen suspensi sangatlah penting dalam pengembangan sumber daya air (water resources).

Berdasarkan dari uraian di atas, cukup layak dilakukan penelitian terkait distribusi sedimen suspensi pada belokan saluran dengan melakukan pengukuran konsentrasi sedimen suspensi. Maka dari itu, dalam penelitian ini akan membahas distribusi sedimen suspensi di belokan pada saluran terbuka.

\section{METODOLOGI PENELITIAN}

Analisis DIstribusi Sedimen dilakukan dengan tahapan sebagai berikut:

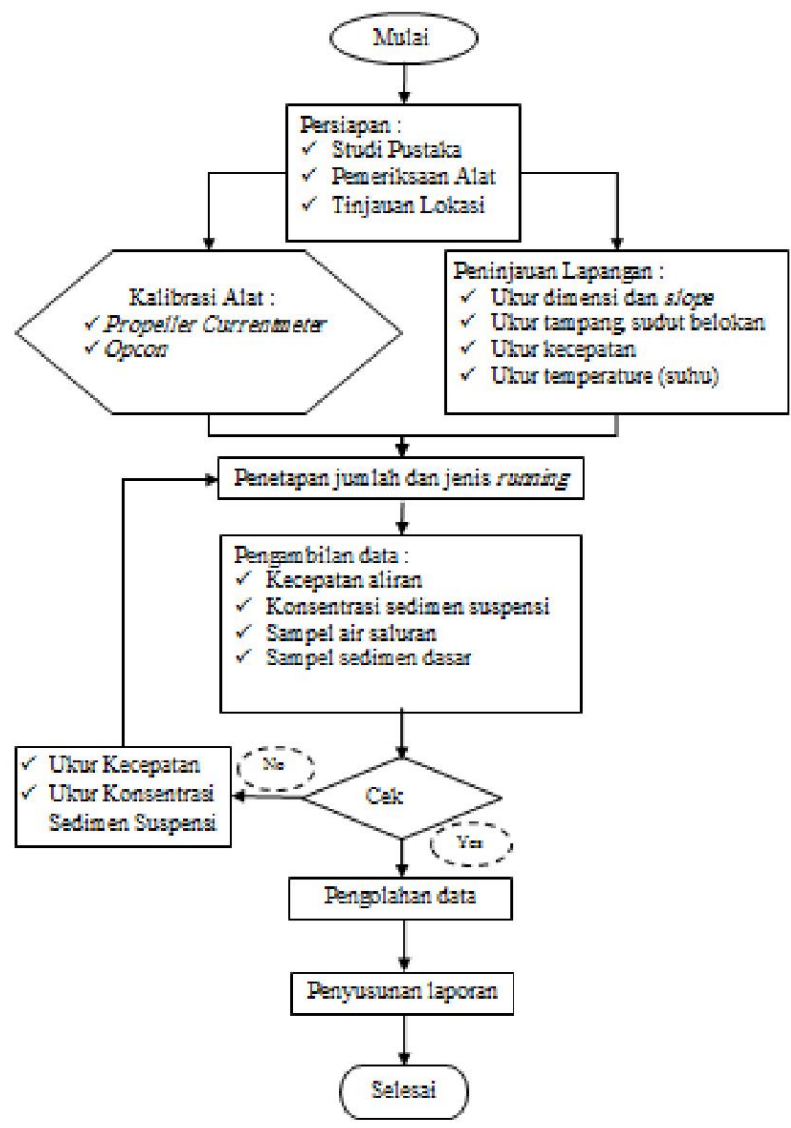

Gambar 1.

Skema Penelitian

Diskripsi Umum. Penelitian ini merupakan pengukuran lapangan yang dilakukan pada belokan Saluran Irigasi Mataram dengan tampang persegi serta material dinding saluran yang bervariasi (beton dan pasangan batu). Penelitian ini menggunakan alat ukur konsentrasi sedimen suspensi Opcon. Adapun lokasi penelitian dapat dilihat pada Gambar dibawah ini:

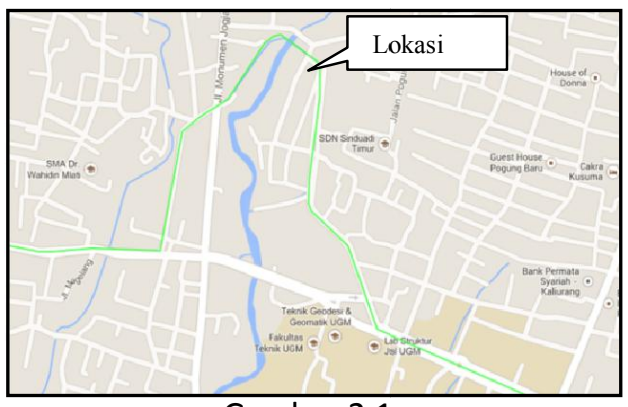

Gambar 2.1

Lokasi Penelitian dengan Google Map

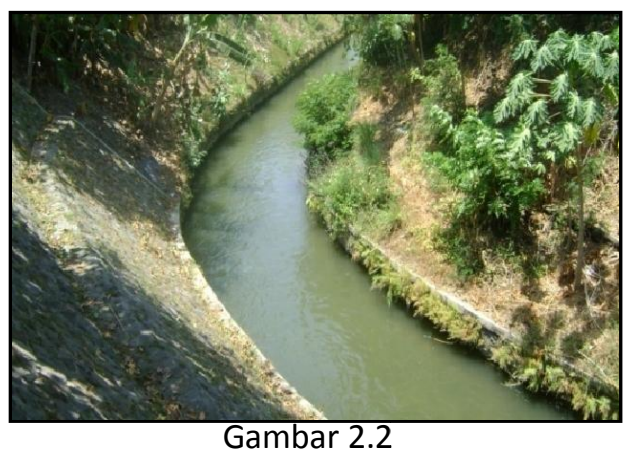

Lokasi Penelitian dengan Foto Lapangan

Prosedur Penelitian. Parameter yang digunakan untuk pengukuran adalah pengukuran arah vertikal dan transversal, dimana arah vertikal (kedalaman) pada posisi yang berbeda dari tepi ke tepi saluran. Secara praktis, titik-titik tersebut ditentukan berdasarkan pembagian pias-pias tampang. Penentuan jarak pengukuran arah transversal tampang dari tepi ke tepi: $1 / 6 B, 1 / 3 B, 1 / 2 B, 2 / 3 B$, dan $5 / 6 B$.

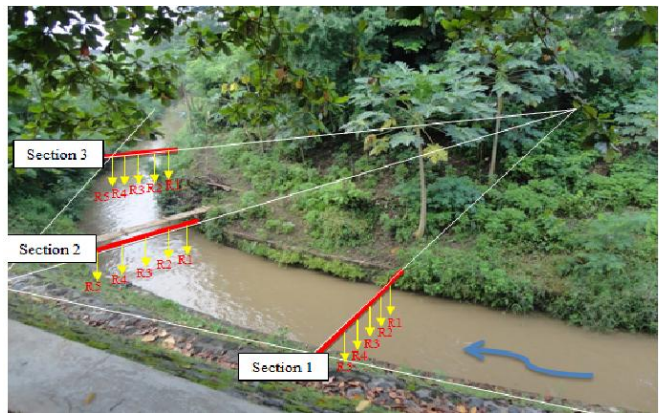

Gambar 3.1

Sketsa titik pengukuran pada tampang aliran

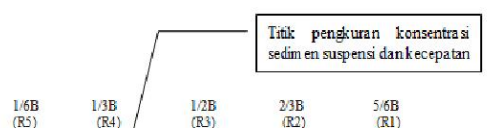


Gambar 3.1

Sketsa titik pengukuran pada tampang aliran

Pengukuran pada satu tampang yang direncanakan seperti pada Gambar 3.1 dan 3.2 adalah :

1. Cross section yang dipilih yaitu : sudut belokan $57^{\circ}$ dipilih cross section pada sudut belokan $0^{\circ}$ (C0), $14.25^{\circ}$ (C14.25), $28.5^{\circ}$ (C28.5), $42.75^{\circ}$ (C42.75), $57^{\circ}$ (C57).

2. Saluran terbuka dengan lebar yang bervariasi disetiap section mulai dari lebar 3,96 $\mathrm{m}$ hingga 4,2 $\mathrm{m}$ dan dibagi menjadi 6 pias dengan jarak yang sama setiap pias.

3. Jarak vertikal antara titik pengukuran adalah interval $2,5 \mathrm{~cm}$ untuk bagian bawah dekat dasar $(0,2 \mathrm{H})$ dan sisanya dengan interval $5 \mathrm{~cm}$. Hal ini dilakukan untuk mendapatkan data pengukuran yang lebih banyak untuk inner region, dimana variasi kecepatan terhadap tinggi lebih besar dibandingkan di outer region.

Alat Opcon. Alat ukur ini mengukur partikel-partikel lanau (silt) dalam aliran suspensi dengan cara memasukkan alat ke dalam aliran yang akan diukur. Hasil dari pengukuran lalu dikalibrasi. Kalibrasi dilakukan dengan mencari hubungan antara bacaan mesin analog sebagai output dari signal processor yang terletak di atas batang opcon dengan suatu nilai konsentrasi sedimen suspensi yang telah diketahui nilai besarannya.

Distribusi Sedimen Suspensi. Untuk analisis sedimen suspensi menggunakan persamaan yang dipublikasikan oleh Rouse, sehingga $z$ sering disebut sebagai parameter Rouse (Rouse number).

$$
\frac{C}{C_{a}}=\left[\frac{D-y}{y} \frac{a}{D-a}\right]^{z}
$$

dengan $C$ sebagai konsentrasi sedimen pada suatu titik berjarak $y$ dari dasar referensi; $C_{a}$, konsentrasi referensi yang berjarak $a$ dari titik referensi; $D$, kedalaman aliran dan $z$ sama dengan parameter Rouse.

Tanaka dan Sugimoto (1958, dalam Garde, 1977) mengusulkan suatu persamaan eksponensial untuk distribusi sedimen suspensi. Dikemukakan bahwa hukum distribusi kecepatan logaritmik Karman-Prandtl yang berasumsi bahwa $\tau$ sama dengan to adalah kurang benar. Oleh sebab itu dengan menggunakan variasi $\tau$ dan $y$ aktual dan diperoleh persamaan baru du/dy, sehingga persamaan Rouse dapat diekspresikan dengan :

$$
\frac{C}{C_{a}}=\left\{\left(\frac{\sqrt{D}+\sqrt{D-y}}{\sqrt{D}-\sqrt{D-y}}\right)\left(\frac{\sqrt{D}-\sqrt{D-a}}{\sqrt{D}+\sqrt{D-a}}\right)\right\}^{\frac{w_{s}}{u_{*} K}}
$$

\section{HASIL DAN PEMBAHASAN}

Parameter Utama Aliran. Penelitian ini merupakan pengukuran lapangan yang dilakukan pada belokan disepanjang Saluran Induk Mataram dengan tampang persegi serta material dinding saluran pasangan batu kali. Adapun parameter utama aliran (running) yang diukur adalah pengukuran distribusi sedimen suspensi. Untuk lokasi pengukuran belokan terletak di depan siphon saluran Mataram.

Pengkodean running didasarkan pada perbedaan lokasi pengukuran, sudut belokan dan kedalaman titik pengukuran. Untuk lokasi pengukuran lapangan (Field) dengan sudut belokan $57^{\circ}$ diawali dengan kode $\mathbf{F}$. Pengukuran pada setiap penampang belokan (Section) dilambangkan dengan huruf $\mathbf{S}$ dan jari-jari setiap belokan yang diukur dari inner bank ke outer bank (Resultan) dilambangkan dengan huruf $\mathbf{R}$ serta pengkodean running tiga karakter FSR masing-masing ditambahkan angka untuk menunjukkan jumlah karakter dan urutan pengukuran yang dimulai dari dasar saluran.

Hasil dari pengukuran dan pendataan di lapangan serta analisis akhir terkait kecepatan aliran, konsentrasi sedimen suspensi serta kemiringan saluran dan debit kecepatan diklasifikasikan sebagai parameter utama aliran. Parameter utama aliran ditampilkan secara detail pada tabel 1 . 
Tabel 1. Parameter Utama Aliran

\begin{tabular}{|c|c|c|c|c|c|c|c|c|c|c|c|c|}
\hline $\begin{array}{c}\text { Kode } \\
\text { Running }\end{array}$ & $\begin{array}{c}\text { Radius } \\
(-)\end{array}$ & $\begin{array}{l}\text { So } \\
(-)\end{array}$ & $\begin{array}{c}B \\
(\mathrm{~m})\end{array}$ & $\begin{array}{l}D \\
(\mathrm{~m})\end{array}$ & $\begin{array}{c}B / D \\
(-)\end{array}$ & $\begin{array}{c}t \\
{ }^{0} \mathrm{C}\end{array}$ & $\begin{array}{c}U \\
\mathbf{m} / \operatorname{det}\end{array}$ & $\begin{array}{c}u *_{c t} \\
\mathbf{m} / \mathbf{d e t}\end{array}$ & $\begin{array}{c}B r \\
10^{5}(-)\end{array}$ & $\begin{array}{c}Q \\
\left(\mathrm{~m}^{3} / \mathrm{det}\right)\end{array}$ & $\begin{array}{l}F r \\
(-)\end{array}$ & $\underset{(\mathrm{gr} / \mathrm{lt})}{\bar{C}}$ \\
\hline F2S1R1 & \multirow{5}{*}{0} & 0.0010 & \multirow{5}{*}{4.15} & 0.65 & 6.38 & 28 & 0.097 & 0.018 & 0.055 & \multirow{5}{*}{0.202} & \multirow{5}{*}{0.03} & 2.499 \\
\hline F2S1R2 & & 0.0010 & & 0.65 & 6.38 & 28 & 0.088 & 0.016 & 0.158 & & & 2.487 \\
\hline F2S1R3 & & 0.0010 & & 0.70 & 5.93 & 28 & 0.082 & 0.016 & 0.833 & & & 2.277 \\
\hline F2S1R4 & & 0.0010 & & 0.55 & 7.55 & 28 & 0.078 & 0.014 & 0.043 & & & 2.045 \\
\hline F2S1R5 & & 0.0010 & & 0.42 & 9.88 & 28 & 0.066 & 0.046 & 2.989 & & & 1.817 \\
\hline F2S2R1 & \multirow{5}{*}{14.25} & 0.0011 & \multirow{5}{*}{4.15} & 0.54 & 7.69 & 29 & 0.086 & 0.049 & 2.836 & \multirow{5}{*}{0.263} & \multirow{5}{*}{0.04} & 3.243 \\
\hline $\mathrm{F} 2 \mathrm{~S} 2 \mathrm{R} 2$ & & 0.0011 & & 0.64 & 6.48 & 29 & 0.085 & 0.010 & 3.661 & & & 3.224 \\
\hline $\mathrm{F} 2 \mathrm{~S} 2 \mathrm{R} 3$ & & 0.0011 & & 0.68 & 6.10 & 29 & 0.099 & 0.014 & 2.056 & & & 3.239 \\
\hline $\mathrm{F} 2 \mathrm{~S} 2 \mathrm{R} 4$ & & 0.0011 & & 0.80 & 5.19 & 29 & 0.102 & 0.007 & 6.419 & & & 3.213 \\
\hline F2S2R5 & & 0.0011 & & 0.78 & 5.32 & 29 & 0.089 & 0.020 & 0.913 & & & 3.156 \\
\hline F2S3R1 & \multirow{5}{*}{28.5} & 0.0012 & \multirow{5}{*}{4.20} & 0.42 & 10.00 & 30 & 0.082 & 0.022 & 1.389 & \multirow{5}{*}{0.265} & \multirow{5}{*}{0.04} & 1.193 \\
\hline F2S3R2 & & 0.0012 & & 0.60 & 7.00 & 30 & 0.099 & 0.010 & 3.431 & & & 1.174 \\
\hline F2S3R3 & & 0.0012 & & 0.70 & 6.00 & 30 & 0.099 & 0.012 & 2.640 & & & 1.198 \\
\hline F2S3R4 & & 0.0012 & & 0.70 & 6.00 & 30 & 0.116 & 0.008 & 7.500 & & & 1.174 \\
\hline F2S3R5 & & 0.0012 & & 0.68 & 6.18 & 30 & 0.113 & 0.008 & 6.909 & & & 1.160 \\
\hline F2S4R1 & \multirow{5}{*}{42.75} & 0.0013 & \multirow{5}{*}{4.15} & 0.48 & 8.65 & 30 & 0.094 & 0.018 & 0.044 & \multirow{5}{*}{0.432} & \multirow{5}{*}{0.05} & 0.830 \\
\hline F2S4R2 & & 0.0013 & & 0.77 & 5.39 & 30 & 0.114 & 0.008 & 7.414 & & & 0.834 \\
\hline F2S4R3 & & 0.0013 & & 0.72 & 5.76 & 30 & 0.114 & 0.024 & 1.286 & & & 0.815 \\
\hline F2S4R4 & & 0.0013 & & 0.85 & 4.88 & 30 & 0.174 & 0.031 & 0.166 & & & 0.974 \\
\hline F2S4R5 & & 0.0013 & & 0.90 & 4.61 & 30 & 0.203 & 0.012 & 12.035 & & & 0.905 \\
\hline F2S5R1 & \multirow{5}{*}{57} & 0.0015 & \multirow{5}{*}{4.15} & 0.80 & 5.19 & 29 & 0.107 & 0.007 & 6.707 & \multirow{5}{*}{0.610} & \multirow{5}{*}{0.05} & 0.869 \\
\hline F2S5R2 & & 0.0015 & & 0.90 & 4.61 & 29 & 0.149 & 0.015 & 3.896 & & & 0.862 \\
\hline F2S5R3 & & 0.0015 & & 0.90 & 4.61 & 29 & 0.180 & 0.009 & 14.109 & & & 0.864 \\
\hline F2S5R4 & & 0.0015 & & 0.95 & 4.37 & 29 & 0.185 & 0.007 & 19.033 & & & 0.853 \\
\hline F2S5R5 & & 0.0015 & & 1.00 & 4.15 & 29 & 0.186 & 0.010 & 12.867 & & & 0.869 \\
\hline
\end{tabular}

Keterangan : $Q=$ debit aliran terukur $\left(\mathrm{m}^{3} /\right.$ det); So $=$ kemiringan dasar saluran; $B=$ lebar flume/saluran $(\mathrm{m}) ; D=$ kedalaman aliran $(\mathrm{m}) ; B / D=$ aspect ratio; $t=$ suhu aliran $\left({ }^{\circ} \mathrm{C}\right) ; \alpha=$ Sudut belokan $\left({ }^{\circ}\right) ; R=$ Jari-jari belokan $(\mathrm{m}) ; U=$ kecepatan aliran $(\mathrm{m} / \mathrm{det}) ; U^{*}=$ kecepatan gesek aliran (m/det); $B r=$ konstanta integrasi dari Log-Low; $F r=U /(g D)^{0.5}$ dan $\bar{C}=$ konsentrasi sedimen suspensi rata-rata tampang (gr/liter).

\section{Distribusi Konsentrasi Sedimen Suspensi}

Dari hasil pengukuran sedimen suspensi, lalu dianalisis sehingga diperoleh data utama yaitu konsentrasi sedimen suspensi.

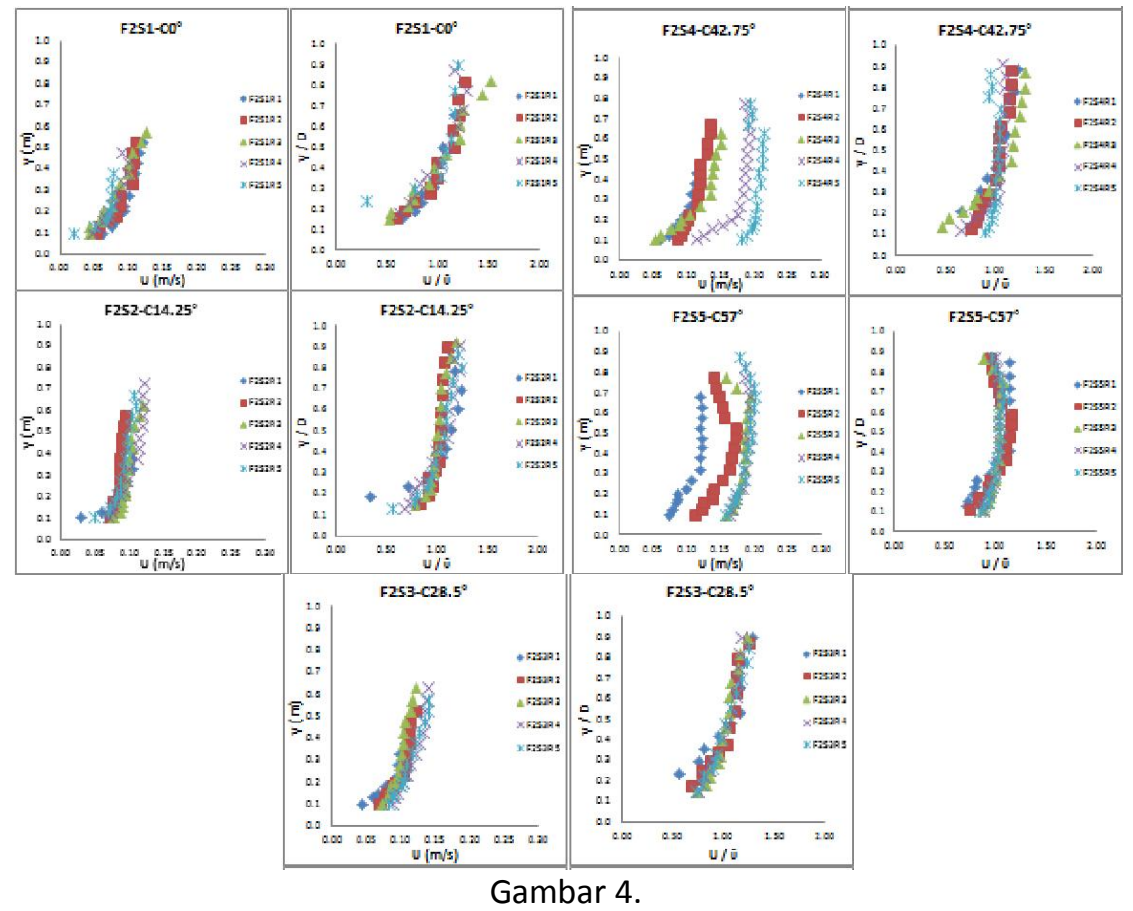

Profil distribusi konsentrasi sedimen suspensi berdimensi dan tak berdimensi pada section $\mathrm{C}^{\circ}$, $\mathrm{C} 14.25^{\circ}, \mathrm{C} 28.5^{\circ}, \mathrm{C} 42.75^{\circ}, \mathrm{C} 57^{\circ}$ dengan $\alpha=57^{\circ}$ 

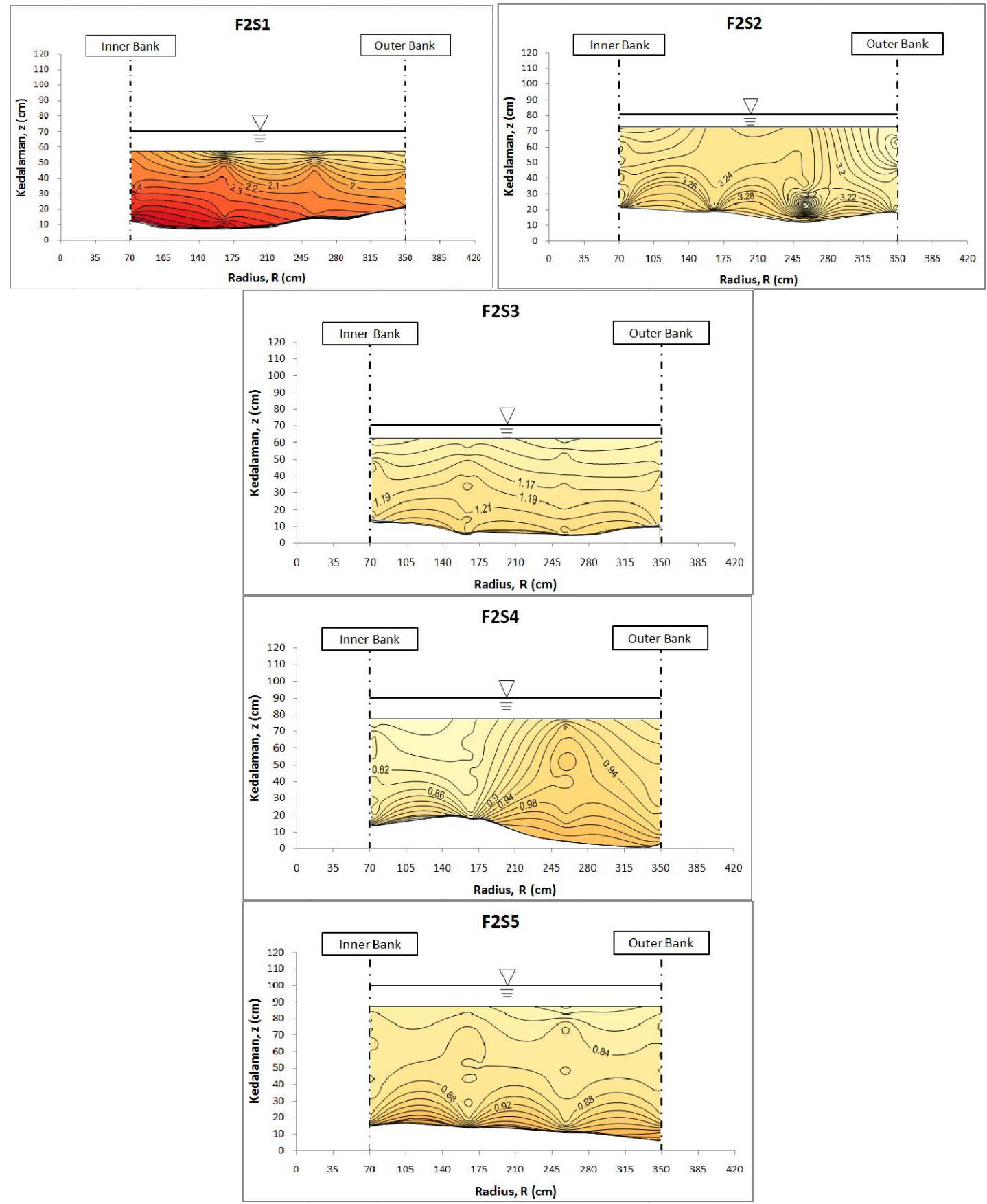

Gambar 5.

Kontur konsentrasi sedimen suspensi pada tiap section dibelokan dengan $\alpha=57^{\circ}$

Dari Gambar 4 dan 5 dapat dijelaskan bahwa Secara umum, distribusi konsentrasi sedimen suspensi hasil pengukuran lapangan belokan dengan sudut, $\alpha=57^{\circ}$ menunjukkan bentuk yang hampir sama untuk seluruh tampang, yaitu konsentrasi sedimen suspensi meningkat kearah dasar saluran dan mengalami penurunan kearah permukaan air dengan trend distribusinya semakin tegak dengan nilai yang semakin seragam kearah permukaan air. Pada arah transversal, konsentrasi sedimen suspensi cenderung meningkat ke arah sisi dalam belokan (inner bank) ketika melewati awal belokan, lalu mengecil kearah sisi dalam belokan (inner bank) saat melewati pertengahan belokan dan kembali meningkat ke arah sisi dalam belokan (inner bank) saat melewati akhir belokan yang mengakibatkan 
terjadinya deposition di sisi dalam belokan (inner bank) dan terjadinya erosion di sisi luar belokan (outer bank).

\section{Distribusi Sedimen Suspensi Dengan Persamaan di Literatur}

Sebagaimana disampaikan pada bab tinjauan pustaka, di literatur banyak dijumpai persamaan-persamaan teoritis/semi teoritis yang dapat dipergunakan untuk menentukan distribusi konsentrasi sedimen suspensi. Diantara beberapa persamaan tersebut, persamaan yang paling populer adalah persamaan Rouse dan persamaan Tanaka-Sugimoto. Oleh karena itu, persamaan Rouse dan Tanaka-Sugimoto digunakan sebagai dasar untuk mengkaji dan membandingkan data distribusi konsentrasi sedimen suspensi yang digunakan dalam tulisan ini dengan persamaanpersamaan di literatur.
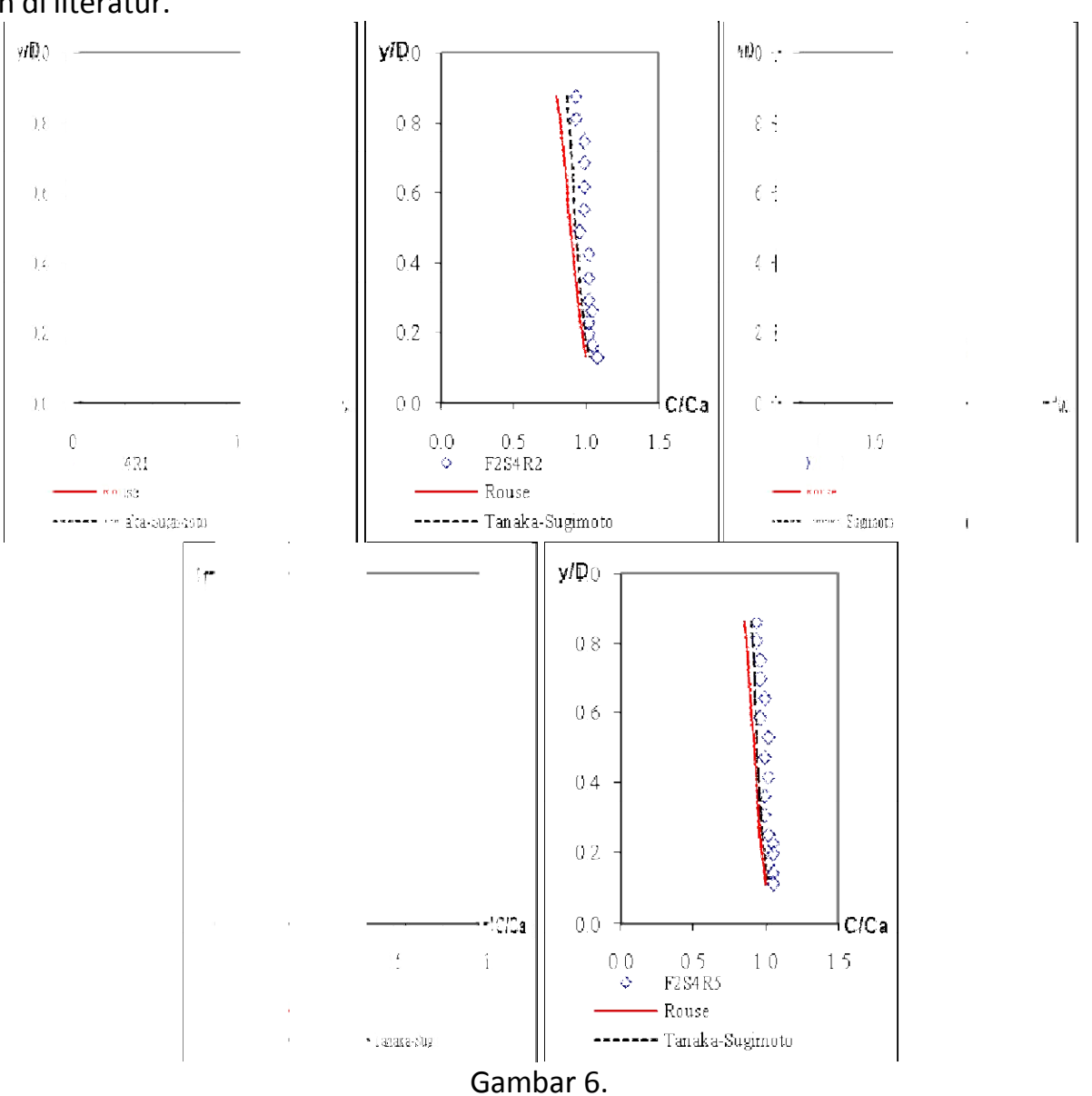

Distribusi Konsentrasi sedimen suspensi hasil pengukuran dibandingkan dengan persamaan Rouse dan Tanaka-Sugimoto untuk aliran pada belokan dengan $\alpha=57^{\circ}$

Dari Gambar 6. menunjukkan bahwa secara umum, analisis distribusi konsentrasi sedimen suspensi hasil pengukuran lapangan yang dibandingkan dengan analisis dari persamaan Rouse dan persamaan TanakaSugimoto menunjukkan bahwa cukup dapat memprediksi data pengukuran distribusi sedimen suspensi pada belokan dimana data hasil pengukuran distribusi sedimen suspensi nilainya mendekati data hasil analisis Rouse dan Tanaka-Sugimoto. Adapun hasil analisis Tanaka-Sugimoto bisa memberikan hasil lebih baik dari analisis Rouse.

\section{KESIMPULAN}

Dari analisis yang dilakukan, maka dapat disimpulkan bahwa:

1. Analisis konsentrasi sedimen suspensi hasil pengukuran lapangan belokan saluran terbuka dengan sudut, $\alpha=57^{\circ}$, 
menunjukkan bahwa trend distribusi konsentrasi sedimen suspensi meningkat kearah dasar saluran dan mengalami penurunan kearah permukaan air dengan trend distribusinya semakin tegak dengan nilai yang semakin seragam kearah permukaan air. Pada arah transversal, konsentrasi sedimen suspensi cenderung meningkat ke arah sisi dalam belokan (inner bank) ketika melewati awal belokan, lalu menurun kearah sisi dalam belokan saat melewati pertengahan belokan dan kembali meningkat ke arah sisi dalam belokan saat melewati akhir belokan yang mengakibatkan terjadinya deposition di sisi dalam belokan (inner bank) dan erosion di sisi luar belokan (outer bank) pada dasar saluran.

2. Analisis distribusi konsentrasi sedimen suspensi hasil pengukuran lapangan yang dibandingkan dengan analisis dari persamaan Rouse dan persamaan TanakaSugimoto menunjukkan bahwa cukup dapat memprediksi data pengukuran distribusi sedimen suspensi pada belokan, meskipun sudut dan jari-jari belokan bervariasi. Data hasil pengukuran sedimen suspense nilainya mendekati data hasil analisis Rouse dan Tanaka-Sugimoto. Adapun hasil analisis Tanaka-Sugimoto bisa memberikan hasil yang lebih baik dari analisis Rouse pada belokan saluran terbuka.

\section{SARAN}

Untuk penelitian lebih lanjut mengenai topik bahasan yang serupa terutama di dalam pengambilan data pembacaan sangat perlu dilakukan pembagian grid yang lebih rapat dan teratur (jarak antar grid yang lebih seragam) terutama pada wilayah dekat dasar saluran (inner region) yang dimulai dari titik referensi $0,2 D$ agar diperoleh data lebih banyak serta data yang lebih seragam dan teratur.

\section{DAFTAR PUSTAKA}

Garde, R. J., and Ranga Raju, K. G., 1977, Mechanics of Sediment Transportation and Alluvial Streams Problems, Wiley Eastern Limited, New Delhi.

Graf, W.H. and M.S. Altinakar, 1998, FLUVIAL HYDRAULICS - Flow and Transport
Processes in Channels of simple Geometry, Presses polytechniques romandes, Lausanne, $\mathrm{CH}$., John Wiley \& Sons Ltd, West Sussex, England.

Kironoto, B.A. 1993, Turbulence Characteristics of Uniformand Non-Uniform Rough Open Channel Flow, Doctoral Disertation. Ecole Plytechnique Federale de lau (EPFL), Switzerland.

Yulistiyanto, B., 1997, Flow Around a Cylinder Installed in a Fixed-Bed Open Channel. Docteur es Sciences Techniques These, Ecole Polytechnique Federale de Lausanne, Lausanne. 